Bond University

Research Repository

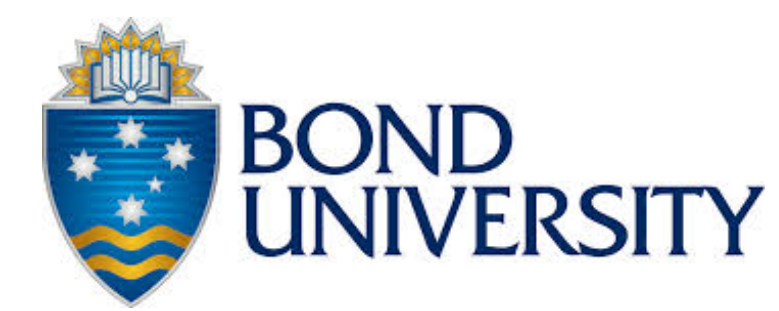

\title{
Analysis of the Effects of Sex and Age on Upper- and Lower-Body Power for Law Enforcement Agency Recruits Before Academy Training
}

Lockie, Robert G.; Dawes, James Jay; Orr, Rob Marc; Stierli, Michael; Dulla, Joseph; Orjalo, Ashley J.

Published in:

Journal of Strength and Conditioning Research

DOI:

10.1519/JSC.0000000000002469

Licence:

Other

Link to output in Bond University research repository.

Recommended citation(APA):

Lockie, R. G., Dawes, J. J., Orr, R. M., Stierli, M., Dulla, J., \& Orjalo, A. J. (2018). Analysis of the Effects of Sex and Age on Upper- and Lower-Body Power for Law Enforcement Agency Recruits Before Academy Training. Journal of Strength and Conditioning Research, 32(7), 1968-1974.

https://doi.org/10.1519/JSC.0000000000002469

\section{General rights}

Copyright and moral rights for the publications made accessible in the public portal are retained by the authors and/or other copyright owners and it is a condition of accessing publications that users recognise and abide by the legal requirements associated with these rights.

For more information, or if you believe that this document breaches copyright, please contact the Bond University research repository coordinator. 
An Analysis of the Effects of Sex and Age on Upper- and Lower-Body Power for Law Enforcement Agency Recruits Prior to Academy Training

\section{Brief Running Head: LEA Recruits and Power}

Robert G. Lockie ${ }^{1}$, J. Jay Dawes ${ }^{2}$, Robin M. Orr ${ }^{3}$, Michael Stierli ${ }^{3,4}$, Joseph M. Dulla ${ }^{5}$, Ashley J. Orjalo $^{1}$

${ }^{1}$ Department of Kinesiology, California State University, Fullerton, Fullerton, CA, USA.

${ }^{2}$ Department of Health Sciences, University of Colorado-Colorado Springs, Colorado Springs, CO, USA.

${ }^{3}$ Tactical Research Unit, Bond University, Robina, Qld, Australia.

${ }^{4}$ Sydney Police Centre, Surry Hills, NSW, Australia.

${ }^{5}$ Recruit Training Unit, Training Bureau, Los Angeles County Sheriff's Department, Los Angeles, CA, USA. 
$\triangle$ Robert Lockie

California State University, Fullerton

Department of Kinesiology

800 N State College Blvd

Fullerton, CA 92831

USA

Phone (international): $\quad+1657-278-3316$

Email:_rlockie@fullerton.edu 


\begin{abstract}
Power is an important characteristic for law enforcement officers. Tasks such as carrying or dragging a civilian to safety, jumping or vaulting, and suspect restraint and pursuit, require power to be effective. Certain recruits may be lacking in these qualities even if they have been accepted to a law enforcement agency (LEA). This study investigated upper- and lower-body power in male and female LEA recruits, and recruits of different ages, prior to academy training. Retrospective analysis of recruit data from one LEA was conducted. The measurements were: vertical jump height (VJ); peak anaerobic power calculated by the Sayers equation; power-tobody mass ratio (P:BM); seated medicine ball throw (MBT) distance; and MBT distance relative to body mass. Independent sample t-tests were used to compare the sexes, while a one-way ANOVA with Bonferonni post hoc compared the pooled data for recruits across different age groups $(20-24 ; 25-29 ; 30-34 ; 35+$ years $)$. The male recruits demonstrated superior performance across all power tests compared to the females $(p<0.001)$. Regarding age, the $35+$ year group performed less than optimally in the VJ and P:BM compared to the 20-24 and 24-29 year groups, and in the relative MBT compared to the 20-24 and 30-34 year groups ( $p=0.003-0.037)$. Despite being accepted to a LEA, females and recruits aged 35+ years of age may be lacking in upper- and lower-body power. Female and older recruits should participate in strength and power training prior to academy attendance to maintain or enhance these qualities.
\end{abstract}

Key words: medicine ball throw; police; Sayers equation; tactical; vertical jump 


\section{INTRODUCTION}

Law enforcement is a physically demanding profession, and places a physiological demand on those employed in this vocation. On-duty law enforcement officers (LEOs) may be required to push, pull, lift, carry, drag, jump, vault, crawl, sprint, use force, and sustain pursuit of a suspect at any time during their shift (17). Several of these tasks, such as carrying or dragging a civilian to safety, jumping or vaulting a barrier or fence, and pursuing a suspect, have a high dependence on power. Power is the ability to generate high amounts of force in short periods of time (19). In athletic populations, numerous studies have documented the benefit of greater upper- and lowerbody power. For example, superior athletes have been shown to demonstrate greater upper-body power as measured by bench throws compared to their lesser counterparts $(1,3)$. Greater lowerbody power as measured by jump performance has been associated with faster running speeds in male $(13,27)$ and female $(45)$ athletes. Power is clearly a quality that has benefit for any individual that needs to perform dynamic tasks. However, there has been less analysis of this quality in law enforcement populations.

Medicine ball throws have been used to provide an indirect measure of upper-body power in the field $(12,20,26)$. Lockie et al. (26) stated that the seated medicine ball throw (MBT) was an effective test of upper-body function in athletic populations. Indeed, the United States (US) army has recently adopted the MBT with a 2-kilogram $(\mathrm{kg})$ ball as part of their Occupational Physical Assessment Test (OPAT) (36). The actions required in the MBT, which involves a forceful extension of the arms, have been related to dynamic activities such as pushing and fending in contact sports (30). This has clear applications for LEOs, as they may need to make contact and physically engage suspects during a shift (17). 
Despite this, there is currently no research that has investigated the use of the MBT as a measure of upper-body power in LEOs, either for recruits or incumbents.

Lower-body power is commonly measured via jump tests $(27,35)$. Although jumping may not provide a direct measure of power, jump assessments are easy to administer (27), provide a valid assessment of an individual's physical capacity (8), and power can be derived via specific formulas $(15,34,42)$. The vertical jump (VJ) has been used to assess lower-body power in different law enforcement populations $(9,11,15,17,18,31,37,38)$. Lower VJ performance scores have been found to relate to an increased risk of injury and illness during academy training in law enforcement agency (LEA) recruits (37). In incumbent officers, Lockie et al. (31) found that younger (20-29 years of age) LEOs performed better in the VJ when compared to older (40-59 years) officers. Dawes et al. (15) found that greater VJ displacement correlated with faster 0-5 meter $(\mathrm{m}), 0-10 \mathrm{~m}$, and 0-20 m sprint times in part-time Special Weapons and Tactics (SWAT) officers (correlation coefficient $[r]=-0.572$ to -0.608 ). Further, Dawes et al. (15) found that relative power calculated from the VJ also correlated with these sprint intervals $(r=-0.561$ to -0.627). Taken together, these studies highlight the value of lower-body power for LEOs.

It is important to note the specific physical qualities of LEA recruits and incumbents, as recent research has shown that this can vary between these populations (38). Most LEAs conduct physical ability testing as part of the hiring process, in an attempt to find candidates that have the requisite physical abilities to complete academy training and the specific tasks required in the occupation. Further to this, LEAs should generally have a non-discriminatory hiring policy regardless of age, sex, and ethnicity for all qualified individuals $(5,32)$. This generally results in academy training classes of individuals with a range of physical abilities. Nonetheless, the job tasks for LEOs will remain the same, regardless of factors such as sex and age. 
This is notable as previous research has shown that incumbent female officers may perform to a lower level in certain physical assessments (e.g. assessments such as the VJ and maximum number of push-ups in 1 minute) when compared to male officers $(7,18,31,38)$. Older incumbent officers may also experience decrements in physical performance (e.g. VJ height, maximum number of push-ups and sit-ups completed in 1 minute, 2.4-kilometer run time), which has been linked to age-related declines in aerobic and anaerobic fitness $(18,31)$, with some research suggesting that the nature of the law enforcement occupation itself has a negative impact on fitness (38). Considering these sex and age differences, the physical training approach that is completed during LEA academy training often features a 'one-size-fits-all' approach (39). This approach could be problematic if the recruits, as suggested above, differ in their physical fitness standards, including their ability to generate power. It would be beneficial to understand whether these qualities vary in LEA recruits prior to academy training with regards to sex and age, and if so, by what degree. This information could prove useful in designing fitness programs for physical training instructors and tactical strength and conditioning facilitators (TSAC-F) who work with LEA academy classes.

Therefore, the purpose of this study was to investigate the effects of sex and age on the upper- and lower-body power characteristics of LEA recruits prior to the start of academy training. A cross-sectional and retrospective analysis of pre-existing data collected from LEA recruits was conducted. The subject data was stratified into males and females, and the pooled (males and females combined) data was also stratified into age groups (20-24 years; 24-29 years; 30-34 years; and 35+ years). Upper-body power was measured via the MBT, and MBT distance was also derived relative to body mass $(25,43)$. Lower-body power was measured by the VJ. 
Peak anaerobic power measured in watts (PAPw), and PAPw relative to body mass (P:BM) was also calculated from the VJ $(15,34)$. It was hypothesized that male and younger recruits would perform better in all power assessments when compared to females and older recruits, respectively.

\section{METHODS}

\section{Experimental Approach to the Problem}

In accordance with previous research $(14-18,31)$, a retrospective analysis of existing data was performed to investigate the effects that sex and age may have upon physical upper- and lowerbody power in LEA recruits prior to academy training. As stated, the candidate pool was stratified into males and females, and the pooled (males and females combined) data was also stratified by age (20-24 years; $24-29$ years; $30-34$ years; and 35+ years). Independent samples ttests were used to compare males and females, while a one-way analysis of variance (ANOVA) was used to separately compare the different age groups. The dependent variables for this study were: VJ height; PAPw; P:BM; MBT distance; and MBT distance relative to body mass.

\section{Subjects}

Data were collected by one US-based LEA in the week preceding academy training, and similar to previous research $(14,15,31)$, was released with consent from that organization. This sample of convenience was comprised of 179 recruits (age: $27.67 \pm 6.18$ years; height: $1.74 \pm 0.09 \mathrm{~m}$; body mass: $78.76 \pm 14.17 \mathrm{~kg}$ ), which included 142 males (age: $27.46 \pm 6.10$ years; height: $1.76 \pm$ $0.08 \mathrm{~m}$; body mass: $82.54 \pm 12.96 \mathrm{~kg}$ ) and 37 females (age: $28.49 \pm 6.52$ years; height: $1.63 \pm$ $0.06 \mathrm{~m}$; body mass: $64.25 \pm 7.88 \mathrm{~kg}$ ). 
This sample incorporated two training cohorts for the LEA that started their academy in the Fall, and any strength and conditioning programs prior to academy were generally completed at the individual-level only by recruits. Based on the archival nature of this analysis $(14-18,31)$, the institutional ethics committee approved the use of pre-existing data. Nonetheless, the study still conformed to the recommendations of the Declaration of Helsinki.

\section{Procedures}

The data in this study were collected by staff working for one LEA using the procedures that are detailed hereafter. The staff were all trained by a certified TSAC-F who verified the proficiency of the staff members. Prior to testing, each subject's age, height, and body mass were recorded. Height was measured barefoot using a portable stadiometer (seca, Hamburg, Germany), while body mass was recorded by electronic digital scales (Health o Meter, Neosho, Missouri). The VJ and MBT were both conducted outdoors on a concrete surface at the LEA's training facility on a day scheduled by the staff for the LEA. Testing typically occurred between the hours of 09001400 depending on recruit availability, and subjects did not eat in the 2-3 hours prior to their testing session. Subjects rotated through the tests in small groups of 3-4 recruits, and were permitted to consume water as required during testing.

\section{Vertical Jump (VJ)}

A Vertec apparatus (Perform Better, Rhode Island, USA) was used to measure the VJ, and followed established assessment protocols $(4,9,28,29)$. The protocols adopted by the LEA staff for the VJ have been shown to have very high test-retest reliability $(r>0.99)(4)$. The subject initially stood side-on to the Vertec (on the subject's dominant side), reached upward as high as 
possible, and fully elevated the shoulder to displace as many vanes as possible, all while keeping their heels on the floor. The last vane moved became the zero reference. The subject then jumped as high as possible, with no preparatory or jab step, and height was recorded from highest vane moved. No restrictions were placed on the range of countermovement during the jump. VJ height was calculated in centimeters $(\mathrm{cm})$ by subtracting the standing reach height from the jump height. Each subject completed two trials, with the best trial used for analysis. Peak power from the VJ was also calculated for the best trial by using the equation from Sayers et al. (42): Peak Power $($ watts; $w)=(60.7 \cdot V J$ height $[\mathrm{cm}])+(45.3 \cdot$ body mass $[\mathrm{kg}])-2055$. PAPw was also calculated relative to body mass to provide a power-to-body mass ratio (P:BM) via the equation: $P: B M=P A P w \cdot B M^{-1}(15,34)$.

\section{Medicine Ball Throw (MBT)}

The MBT was used to indirectly measure isolated upper-body power, and the protocols utilized were adapted from previous research $(12,20,26)$, which have been shown to have high testretest reliability $(r>0.95)(20)$. Subjects sat on the ground with their head, shoulders, and lower back against a concrete wall. They then extended their legs horizontally on the floor in front of the body, and maintained this position throughout the MBT trials. Similar to the US Army's OPAT (36), subjects projected a 2-kg medicine ball (Champion Barbell, Texas, USA) as far as possible using a two-handed chest pass, without the head, shoulders, and hips moving from the wall. The medicine ball was lightly dusted with chalk to allow subjects to grip the ball, and also to mark the ground where the ball landed after the throw (26). The measurement taken, using a standard tape measure, was the perpendicular distance from the wall to the chalk-marking closest to the wall made by the ball $(26,36)$. 
No limitations were placed on the height of the throw. Two trials were completed, and the best trial was used for analysis. To provide a further measure of upper-body power, the MBT distance was also made relative to body mass via the formula: relative $M B T=$ throw distance $\cdot$ body mass $^{-1}$ $(25,43)$.

\section{Statistical Analysis}

Statistical analyses were processed using the Statistics Package for Social Sciences (Version 24; IBM Corporation, New York, USA), and Microsoft Excel (Microsoft Corporation ${ }^{\mathrm{TM}}$, Redmond, Washington, USA). As stated, the sample was stratified by sex (males and females) and age (2024 years, 25-29 years, 30-34 years, and 35+ years). Descriptive data (mean \pm standard deviation [SD]; 95\% confidence intervals [CI]) were calculated for each of these groups. An independent samples t-test was used to compare the male and female groups, with significance set at $p<0.05$. To compare the age groups, a one-way ANOVA was utilized $(p<0.05)$, with a Bonferroni post hoc for multiple pairwise comparisons. Effect sizes $(d)$ were also calculated for the betweengroup comparisons for sex and age, where the difference between the means was divided by the pooled SD (10). In accordance with Hopkins (21), a $d$ less than 0.2 was considered a trivial effect; 0.2 to 0.6 a small effect; 0.6 to 1.2 a moderate effect; 1.2 to 2.0 a large effect; 2.0 to 4.0 a very large effect; and 4.0 and above an extremely large effect. 


\section{RESULTS}

The data for the male and female groups are shown in Table 1. The male recruits demonstrated significantly higher power results in all tests. There were very large effect sizes for the differences in PAPw and absolute MBT. The difference between the sexes in the VJ and P:BM had large effect sizes, while the between-sex difference for relative MBT had a moderate effect size.

\section{***INSERT TABLE 1 ABOUT HERE***}

The data for the different age groups are shown in Table 2, with the effect size data in Table 3. The 20-24 year $(p=0.021)$ and 25-29 year $(p=0.042)$ groups had a significantly greater VJ when compared to the 35+ year group. The 20-24 year $(p=0.003)$ and 25-29 year $(p=0.020)$ groups also had a significantly greater P:BM when compared to the $35+$ year group. With regards to the relative MBT, the 20-24 year $(p=0.014)$ and 30-34 year $(p=0.037)$ groups were superior to the $35+$ year group. There were no significant between-group differences in PAPw ( $p$ $=0.253)$ or the MBT $(p=0.187)$. All significant differences had moderate effect sizes.

\footnotetext{
***INSERT TABLE 2 ABOUT HERE***

***INSERT TABLE 3 ABOUT HERE***
}

\section{DISCUSSION}

This study investigated the effects that sex and age may have had on the upper-body power, as measured by the MBT, and the lower-body power, as measured by the VJ, of LEA recruits prior 
to academy training. The results indicated that both female recruits and older recruits above 35 years of age tended to perform lower in power assessments when compared to male recruits and younger recruits, respectively. Given the likely importance of power to specific policing tasks such as such as jumping or vaulting barriers and suspect pursuit $(15,17)$, as well as the link between better jump performance and the reduction of illness and injury risk during the academy period (37), these results are notable. The findings from this study have important implications for TSAC-F and strength and conditioning coaches who work with LEA recruits. As will be discussed, female recruits and older recruits preparing to enter an LEA for training should attempt to develop their upper- and lower-body power prior to the academy period as they may be deficient in these capacities when compared to other recruits in their training classes. This would be especially problematic if the training approach for the LEA is 'one-size-fits-all' (39) and given that the job demands do not vary regardless of the sex or age of the recruit (5).

The results from this study showed that the male recruits scored higher than the female recruits in all power assessments (i.e. both upper- and lower-body). This result was in line with the study's hypothesis, given that males, in general, tend to carry more lean body mass when compared to females (22), and previous research has shown that male incumbent officers tend to perform better in tests of power when compared to female incumbents $(7,18,38)$. The VJ height for the males in this study were similar to that from police cadets $(59.1 \pm 11.1 \mathrm{~cm})(11)$, incumbent LEOs $(\sim 53 \mathrm{~cm})(31)$, incumbent highway patrol officers $(50.74 \pm 8.89 \mathrm{~cm})(18)$, and part-time SWAT officers $(55.40 \pm 6.7 \mathrm{~cm})(15)$ from across the US. The mean VJ height for the females from this study was similar to that for police cadets $(39.9 \pm 4.5 \mathrm{~cm})(11)$, and incumbent LEOs $(\sim 34 \mathrm{~cm})(31)$ and highway patrol officers $(36.80 \pm 5.69 \mathrm{~cm})(18)$ from across the US. Collectively, this data indicated the subjects from this research are representative of LEOs, 
which provides practical application for the current results. As female recruits will often need to perform the same tasks as males during physical training (39) and on the job (5), they may be at an initial disadvantage in power-based activities. On this basis, female recruits should attempt to develop their upper- and lower-body power prior to the academy period with the guidance of TSAC-F and strength and conditioning coaches. This approach could assist in lowering the chance of injury and illness (37), while also enhancing the ability to perform job-related training tasks (e.g. defensive tactics and running training).

Similar to previous research (31), data were pooled for the age group comparisons. With regards to the $\mathrm{VJ}$, the $35+$ year group had a significantly lower jump heights and P:BMs when compared to the 20-24 and 25-29 year groups, and all comparisons had moderate effect sizes. The value of these variables was highlighted by Dawes et al. (15), who documented that greater VJ height and P:BM related to faster 20-m sprint times in part-time male SWAT officers. In contrast, there were no significant between-group differences in PAPw. Interestingly, Dawes et al. (15) found that PAPw derived from the VJ did not significantly correlate with 20-m sprint times in part-time male SWAT officers. Nonetheless, the results from this study highlight that recruits aged $35+$ years performed lower in the $\mathrm{VJ}$, and in the generation of lower-body power relative to body mass. This has also been seen in older incumbent officers when analyzed in cross-sectional studies $(18,31)$, and may reflect age-related changes in fast-twitch muscle fiber size (23) and lean tissue mass (22). As noted, given that the demands of physical training will generally not vary regardless of the population subsets within an academy class (39), older recruits should complete specific training to ensure the maintenance or improvement of absolute and relative lower-body power. 
This should positively contribute to jumping, vaulting, and running tasks $(13,27,45)$, as well as injury and illness prevention (37). TSAC-F and strength and conditioning coaches should consider this information when designing programs for older LEA recruits.

There is currently no research that has measured the performance of the MBT in law enforcement populations. This is despite the fact that the actions required in the MBT (i.e. a powerful extension of the arms) could manifest in job-related tasks (i.e. a physical altercation with a suspect) (17). Lockie et al. (26) stated that the MBT was an appropriate test of upper-body function, and found that recreational male team sport athletes projected a $1-\mathrm{kg}$ medicine ball a distance of approximately $7.66 \mathrm{~m}$. However, this study used the MBT as implemented by the US Army, which utilizes a $2 \mathrm{~kg}$ ball (36). There were no significant differences between the different age groups when considering the MBT distance. Indeed, all age groups exceeded the minimum MBT distance of $4.50 \mathrm{~m}$ required for an infantry, armor, and artillery position in the US Army (44). However, when considering MBT distance relative to body mass, the $35+$ year group performed lower than the 20-24 and 30-34 year groups. Similar to the P:BM as measured from the $\mathrm{VJ}$, older recruits appeared to have a deficiency in the ability to generate upper-body power relative to body mass. As upper-body power could positively contribute to tasks required in defensive tactics training (e.g. grappling, wrestling, and striking) $(6,40)$, in addition to jobrelated tasks (17), this is also a capacity that older recruits should attempt to optimize prior to academy.

There are certain study limitations that should be acknowledged. There were more males than females analyzed in this study, although this is typical for LEA populations $(9,11,18,31$, 41). Nevertheless, future research should attempt to analyze more female LEA recruits to garner more information about this population. 
This study only utilized one upper- and lower-body power test each. Although this was due to time constraints when assessing LEA recruit populations prior to the start of an academy, this limited the interpretation of power characteristics in this population. Future research should investigate other measures of upper- and lower-body power, including loaded bench throws (2), a backwards overheard medicine ball toss $(25,33)$, and standing broad and lateral jumps (28, 29). Furthermore, future research should also document how measures of upper- and lower-body power, such as the MBT and VJ, change after the academy training period. Within the context of these limitations, the results from the current study showed that female recruits, and recruits older than 35 years of age, should complete a strength and conditioning program that eventually is aimed at improving strength and power outcomes prior to attending an academy. An appropriate program that develops upper- and lower-body power could assist with injury and illness prevention (37), as well as performance in job-specific training tasks that require power $(6,15,17,40)$.

\section{PRACTICAL APPLICATIONS}

There are several practical applications that can be drawn from this research. TSAC-F and strength and conditioning coaches who work with LEA recruits should consider the following information when preparing individuals for academy training. Female LEA recruits should complete strength and power training to develop these qualities prior to their commencement of training at a LEA academy. Even though they have been accepted to a LEA, the inherent physiology of female recruits may place them at a disadvantage when compared to their male counterparts. Structured, long-term resistance training has been shown to positively influence the occupational performance of women in the military (24), and this would also have application for female LEA recruits. 
Older recruits (i.e. $35+$ years of age), should also complete strength and power training prior to academy attendance to maintain or develop their ability to generate upper- and lower-body power relative to body mass. The completion of power training can have a positive influence on muscle function and fast-twitch muscle fiber size in older individuals (23), so this approach should be adopted by older LEA recruits as long as possible prior to academy attendance. Further to this, training instructors may consider utilizing ability-based training rather than a 'one-sizefits-all' approach in order to more appropriately develop power across an academy class (39).

\section{ACKNOWLEDGEMENTS}

This research project received no external financial assistance. None of the authors have any conflict of interest. The authors would like to thank the training instructors for facilitating this research, and the California State University, Fullerton tactical research team for collating the data.

\section{REFERENCES}

1. Baker, D. Comparison of upper-body strength and power between professional and college-aged rugby league players. J Strength Cond Res. 15(1):30-35. 2001.

2. Baker, D., S. Nance, and M. Moore. The load that maximizes the average mechanical power output during explosive bench press throws in highly trained athletes. $J$ Strength Cond Res. 15(1):20-24. 2001.

3. Baker, D. Differences in strength and power among junior-high, senior-high, collegeaged, and elite professional rugby league players. J Strength Cond Res. 16(4):581-585. 2002. 
4. Beck, A.Q., J.L. Clasey, J.W. Yates, N.C. Koebke, T.G. Palmer, and M.G. Abel. Relationship of physical fitness measures vs. occupational physical ability in campus law enforcement officers. J Strength Cond Res. 29(8):2340-2350. 2015.

5. Birzer, M.L. and D.E. Craig. Gender differences in police physical ability test performance. Am J Police. 15(2):93-108. 1996.

6. Bounty, P.L., B.I. Campbell, E. Galvan, M. Cooke, and J. Antonio. Strength and conditioning considerations for Mixed Martial Arts. Strength Cond J. 33(1):56-67. 2011.

7. Boyce, R.W., G.R. Jones, K.E. Schendt, C.L. Lloyd, and E.L. Boone. Longitudinal changes in strength of police officers with gender comparisons. J Strength Cond Res. 23(8):2411-2418. 2009.

8. Burr, J.F., V.K. Jamnik, S. Dogra, and N. Gledhill. Evaluation of jump protocols to assess leg power and predict hockey playing potential. J Strength Cond Res. 21(4):11391145. 2007.

9. Cocke, C., J. Dawes, and R.M. Orr. The use of 2 conditioning programs and the fitness characteristics of police academy cadets. J Athl Train. 51(11):887-896. 2016.

10. Cohen, J. Statistical Power Analysis for the Behavioral Sciences 2nd ed. Hillsdale, New Jersey: Lawrence Earlbaum Associates, 1988.

11. Crawley, A.A., R.A. Sherman, W.R. Crawley, and L.M. Cosio-Lima. Physical fitness of police academy cadets: Baseline characteristics and changes during a 16-week academy. J Strength Cond Res. 30(5):1416-1424. 2016.

12. Cronin, J.B. and G.J. Owen. Upper-body strength and power assessment in women using a chest pass. J Strength Cond Res. 18(3):401-404. 2004. 
13. Cronin, J.B. and K.T. Hansen. Strength and power predictors of sports speed. J Strength Cond Res. 19(2):349-357. 2005.

14. Dawes, J.J., R.M. Orr, C.L. Elder, and C. Rockwell. Association between body fatness and measures of muscular endurance among part-time SWAT officers. J Aust Strength Cond. 22(4):33-37. 2014.

15. Dawes, J.J., R.M. Orr, C.L. Elder, K. Krall, M. Stierli, and B. Schilling. Relationship between selected measures of power and strength and linear running speed amongst Special Weapons and Tactics police officers. J Aust Strength Cond. 23(3):23-28. 2015.

16. Dawes, J.J., R.M. Orr, B.L. Brandt, R.L. Conroy, and R. Pope. The effect of age on pushup performance amongst male law enforcement officers. $J$ Aust Strength Cond. 24(4):2327. 2016.

17. Dawes, J.J., R.M. Orr, C.L. Siekaniec, A.A. Vanderwoude, and R. Pope. Associations between anthropometric characteristics and physical performance in male law enforcement officers: A retrospective cohort study. Ann Occup Environ Med. 28(26): doi:10.1186/s40557-40016-40112-40555. 2016.

18. Dawes, J.J., R.M. Orr, R.R. Flores, R.G. Lockie, C. Kornhauser, and R. Holmes. A physical fitness profile of state highway patrol officers by gender and age. Ann Occup Environ Med. 29: doi:10.1186/s40557-40017-40173-40550. 2017.

19. Haff, G.G. and S. Nimphius. Training principles for power. Strength Cond J. 34(6):2-12. 2012.

20. Harris, C., A.P. Wattles, M. Debeliso, P.G. Sevene-Adams, J.M. Berning, and K.J. Adams. The seated medicine ball throw as a test of upper body power in older adults. $J$ Strength Cond Res. 25(8):2344-2348. 2011. 
21. Hopkins, W.G. How to interpret changes in an athletic performance test. Sportscience. 8:1-7. 2004.

22. Janssen, I., S.B. Heymsfield, Z. Wang, and R. Ross. Skeletal muscle mass and distribution in 468 men and women aged 18-88 yr. J Appl Physiol. (89):81-88. 2000.

23. Korhonen, M.T., A. Cristea, M. Alén, K. Häkkinen, S. Sipilä, A. Mero, J.T. Viitasalo, L. Larsson, and H. Suominen. Aging, muscle fiber type, and contractile function in sprinttrained athletes. J Appl Physiol. 101(3):906-917. 2006.

24. Kraemer, W.J., S.A. Mazzetti, B.C. Nindl, L.A. Gotshalk, J.S. Volek, J.A. Bush, J.O. Marx, K. Dohi, A.L. Gomez, M. Miles, S.J. Fleck, R.U. Newton, and K. Hakkinen. Effect of resistance training on women's strength/power and occupational performances. Med Sci Sports Exerc. 33(6):1011-1025. 2001.

25. Lockie, R.G., M.D. Jeffriess, A.B. Schultz, and S.J. Callaghan. Relationship between absolute and relative power with linear and change-of-direction speed in junior American football players from Australia. J Aust Strength Cond. 20(4):4-12. 2012.

26. Lockie, R.G., S.J. Callaghan, C.A. Jordan, T.M. Luczo, and M.D. Jeffriess. Does the trunk stability push-up provide an effective measure of upper-body function specific to male team sport athletes? J Athl Enhancement. 2(4):doi:10.4172/2324-9080.1000120. 2013.

27. Lockie, R.G., S.J. Callaghan, S.P. Berry, E.R. Cooke, C.A. Jordan, T.M. Luczo, and M.D. Jeffriess. Relationship between unilateral jumping ability and asymmetry on multidirectional speed in team-sport athletes. J Strength Cond Res. 28(12):3557-3566. 2014. 
28. Lockie, R.G., A.B. Schultz, S.J. Callaghan, C.A. Jordan, T.M. Luczo, and M.D. Jeffriess. A preliminary investigation into the relationship between functional movement screen scores and athletic physical performance in female team sport athletes. Biol Sport. 32(1):41-51. 2015.

29. Lockie, R.G., A.B. Schultz, C.A. Jordan, S.J. Callaghan, M.D. Jeffriess, and T.M. Luczo. Can selected functional movement screen assessments be used to identify movement deficiencies that could affect multidirectional speed and jump performance? J Strength Cond Res. 29(1):195-205. 2015.

30. Lockie, R.G., S.J. Callaghan, M.R. Moreno, F.G. Risso, T.M. Liu, A.A. Stage, S.A. Birmingham-Babauta, J.J. Stokes, D.V. Giuliano, A. Lazar, D.L. Davis, and A.J. Orjalo. An investigation of the mechanics and sticking region of a one-repetition maximum close-grip bench press versus the traditional bench press. Sports. 5(3): doi:10.3390/sports5030046. 2017.

31. Lockie, R.G., J.J. Dawes, C.L. Kornhauser, and R.J. Holmes. A cross-sectional and retrospective cohort analysis of the effects of age on flexibility, strength endurance, lower-body power, and aerobic fitness in law enforcement officers. J Strength Cond Res: doi:10.1519/jsc.0000000000001937. in press.

32. Los Angeles County Sheriff's Department (2015). Deputy Sheriff Trainee. Available at: http://agency.governmentjobs.com/lacounty/job_bulletin.cfm?jobID=1181988\&sharedWi ndow=0. Accessed November 11, 2017.

33. Marques, M.C., R. Van Den Tillaar, T.J. Gabbett, V.M. Reis, and J.J. Gonzalez-Badillo. Physical fitness qualities of professional volleyball players: determination of positional differences. J Strength Cond Res. 23(4):1106-1111. 2009. 
34. McFarland, I., J.J. Dawes, C.L. Elder, and R.G. Lockie. Relationship of two vertical jumping tests to sprint and change of direction speed among male and female collegiate soccer players. Sports. 4(1):doi:10.3390/sports4010011. 2016.

35. Meylan, C., T. Mcmaster, J. Cronin, N.I. Mohammad, C. Rogers, and M. Deklerk. Single-leg lateral, horizontal, and vertical jump assessment: reliability, interrelationships, and ability to predict sprint and change-of-direction performance. J Strength Cond Res. 23(4):1140-1147. 2009.

36. Military Performance Division (2015). Development of the Occuptational Physical Assessment Test (OPAT) for Combat Arms Soldiers. Available at: https://www.defense.gov/Portals/1/Documents/wisr-studies/Army\%20-

\%20MEDCOM\%20USARIEM\%20Task\%20Assessment3.pdf. Accessed November 10, 2017.

37. Orr, R., R. Pope, S. Peterson, B. Hinton, and M. Stierli. Leg power as an indicator of risk of injury or illness in police recruits. Int J Environ Res Public Health. 13(2): doi:10.3390/ijerph13020237. 2016.

38. Orr, R., J.J. Dawes, R. Pope, and J. Terry. Assessing differences in anthropometric and fitness characteristics between police academy cadets and incumbent officers. J Strength Cond Res. Publish Ahead of Print: doi:10.1519/JSC.0000000000002328. in press.

39. Orr, R.M., K. Ford, and M. Stierli. Implementation of an ability-based training program in police force recruits. J Strength Cond Res. 30(10):2781-2787. 2016.

40. Ratamess, N.A. Strength and conditioning for grappling sports. Strength Cond J. 33(6):18-24. 2011. 
41. Rossomanno, C.I., J.E. Herrick, S.M. Kirk, and E.P. Kirk. A 6-month supervised employer-based minimal exercise program for police officers improves fitness. J Strength Cond Res. 26(9):2338-2344. 2012.

42. Sayers, S.P., D.V. Harackiewicz, E.A. Harman, P.N. Frykman, and M.T. Rosenstein. Cross-validation of three jump power equations. Med Sci Sports Exerc. 31(4):572-577. 1999.

43. Stockbrugger, B.A. and R.G. Haennel. Contributing factors to performance of a medicine ball explosive power test: a comparison between jump and nonjump athletes. $J$ Strength Cond Res. 17(4):768-774. 2003.

44. U.S. Army Center for Initial Military Training (2016). Occuptaional Physical Assessment $\begin{array}{lll}\text { Test } & \text { Scorecard. Available at: }\end{array}$ http://www.ssi.army.mil/!CareerAdvisor/Mr.\%20Wilcox\%20uploads/HQDA\%20EXOR D\%20202-16\%20Att\%202\%20-\%20OPAT\%20Scorecard.pdf. Accessed November 17, 2017.

45. Vescovi, J.D. and M.R. Mcguigan. Relationships between sprinting, agility, and jump ability in female athletes. J Sports Sci. 26(1):97-107. 2008.

\section{Table Legend}

Table 1: Descriptive statistics (mean \pm SD; $95 \%$ CI) for the vertical jump (VJ), peak anaerobic power measured in watts (PAPw), power-to-body mass ratio (P:BM), medicine ball throw (MBT), and relative MBT (RMBT) in male and female law enforcement agency recruits prior to academy training.

Table 2: Descriptive statistics (mean $\pm \mathrm{SD} ; 95 \% \mathrm{CI}$ ) for the vertical jump (VJ), peak anaerobic power measured in watts $(\mathrm{PAPw})$, power-to-body mass ratio $(\mathrm{P}: \mathrm{BM})$, medicine ball throw 
(MBT), and relative MBT (RMBT) in law enforcement agency recruits stratified by age (20-24 years, 25-29 years, 30-34 years, and 35+ years) prior to academy training.

Table 3: Pairwise effect size data for the vertical jump (VJ), peak anaerobic power measured in watts (PAPw), power-to-body mass ratio (P:BM), medicine ball throw (MBT), and relative MBT (RMBT) in law enforcement agency recruits stratified by age (20-24 years, 25-29 years, 30-34 years, and 35+ years) prior to academy training. 
Table 1: Descriptive statistics (mean $\pm \mathrm{SD} ; 95 \% \mathrm{CI}$ ) for the vertical jump (VJ), peak anaerobic power measured in watts (PAPw), power-to-body mass ratio (P:BM), medicine ball throw (MBT), and relative MBT (RMBT) in male and female law enforcement agency recruits prior to academy training.

\begin{tabular}{cccccc}
\hline & Males $(\mathrm{n}=142)$ & Females $(\mathrm{N}=37)$ & $p$ & $d$ strength \\
\hline VJ $(\mathrm{cm})$ & $54.36 \pm 11.21(52.50-56.22)$ & $38.20 \pm 10.34 *(34.76-41.65)$ & $<0.001$ & 1.50 & Large \\
PAPw (watts) & $4984.20 \pm 950.51(4826.51-5141.89)$ & $3174.46 \pm 744.40 *(2926.26-3422.65)$ & $<0.001$ & 2.12 & Very Large \\
P:BM (watts $\left.\cdot \mathrm{kg}^{-1}\right)$ & $60.60 \pm 8.79(59.14-62.06)$ & $49.35 \pm 9.90 *(46.04-52.65)$ & $<0.001$ & 1.20 & Large \\
MBT (m) & $6.21 \pm 0.99(6.04-6.37)$ & $4.01 \pm 0.61 *(3.81-4.22)$ & $<0.001$ & $2.68 \quad$ Very Large \\
RMBT $\left(\mathrm{m} \cdot \mathrm{kg}^{-1}\right)$ & $0.076 \pm 0.013(0.074-0.078)$ & $0.063 \pm 0.009 *(0.060-0.066)$ & $<0.001$ & 1.16 & Moderate \\
\hline
\end{tabular}

* Significantly $(p<0.05)$ lower than the males. 
Table 2: Descriptive statistics (mean $\pm \mathrm{SD} ; 95 \% \mathrm{CI}$ ) for the vertical jump (VJ), peak anaerobic power measured in watts (PAPw), power-to-body mass ratio (P:BM), medicine ball throw (MBT), and relative MBT (RMBT) in law enforcement agency recruits stratified by age (20-24 years, 25-29 years, 30-34 years, and 35+ years) prior to academy training.

\begin{tabular}{ccccc}
\hline & $20-24$ years $(\mathrm{n}=59)$ & $25-29$ years $(\mathrm{n}=75)$ & $30-34$ years $(\mathrm{n}=22)$ & $35+$ years $(\mathrm{n}=23)$ \\
\hline Age (years) & $22.47 \pm 1.14$ & $26.53 \pm 1.43$ & $32.05 \pm 1.43$ & $40.52 \pm 5.35$ \\
& $(22.18-22.77)$ & $(26.21-26.86)$ & $(31.41-32.68)$ & $(38.21-42.84)$ \\
Height (m) & $1.73 \pm 0.09$ & $1.74 \pm 0.09$ & $1.74 \pm 0.09$ & $1.72 \pm 0.10$ \\
& $(1.71-1.75)$ & $(1.72-1.76)$ & $(1.70-1.78)$ & $(1.68-1.76)$ \\
Body Mass (kg) & $76.31 \pm 12.54$ & $80.48 \pm 14.03$ & $78.24 \pm 13.33$ & $79.97 \pm 18.69$ \\
& $(73.04-79.58)$ & $(77.25-83.71)$ & $(72.33-84.15)$ & $(71.88-88.05)$ \\
VJ (cm) & $53.21 \pm 12.45$ & $52.22 \pm 12.79$ & $48.36 \pm 12.71$ & $44.06 \pm 11.86 * \S$ \\
PAPw (watts) & $(49.96-56.45)$ & $(49.28-55.16)$ & $(42.73-54.00)$ & $(38.93-49.19)$ \\
P:BM (watts·kg $\left.{ }^{-1}\right)$ & $4631.32 \pm 1068.14$ & $4760.70 \pm 1174.58$ & $4424.66 \pm 1071.91$ & $4424.12 \pm 1437.71$ \\
MBT (m) & $(4352.96-4909.68)$ & $(4490.45-5030.95)$ & $(3949.40-4899.91)$ & $(3620.41-4863.83)$ \\
RMBT (m.kg $\left.{ }^{-1}\right)$ & $60.60 \pm 10.27$ & $58.89 \pm 9.82$ & $56.57 \pm 9.46$ & $51.94 \pm 8.74 * \S$ \\
& $(57.93-63.28)$ & $(56.63-61.15)$ & $(52.37-60.76)$ & $(48.17-55.72)$ \\
& $5.72 \pm 1.28$ & $5.89 \pm 1.23$ & $5.92 \pm 1.15$ & $5.25 \pm 1.48$ \\
\end{tabular}

* Significantly $(p<0.05)$ lower than the 20-24 year group.

$\S$ Significantly $(p<0.05)$ lower than the 25-29 year group.

$¥$ Significantly $(p<0.05)$ lower than the $30-34$ year group. 
Table 3: Pairwise effect size data for the vertical jump (VJ), peak anaerobic power measured in watts (PAPw), power-to-body mass ratio (P:BM), medicine ball throw (MBT), and relative MBT (RMBT) in law enforcement agency recruits stratified by age (20-24 years, 25-29 years, 30-34 years, and 35+ years) prior to academy training.

\begin{tabular}{|c|c|c|c|c|c|c|}
\hline & $20-24-25-29$ & $20-24-30-34$ & $20-24-35+$ & $25-29-30-34$ & $25-29-35+$ & $30-34-35+$ \\
\hline $\mathrm{VJ}$ & 0.08 & 0.39 & $0.75^{*}$ & 0 . & $0.66^{*}$ & 0.35 \\
\hline PAPw & 0.12 & 0.19 & 0.16 & & 0.26 & $<0.01$ \\
\hline $\mathrm{P}: \mathrm{BM}$ & 0.17 & 0.41 & 0.9 & 0.24 & $0.75 *$ & 0.51 \\
\hline MBT & 0.14 & 0.16 & & 0.03 & 0.47 & 0.51 \\
\hline RMBT & 0.13 & 0.07 & & 0.22 & 0.57 & $0.94 *$ \\
\hline
\end{tabular}

\footnotetext{
* Moderate effect for the pairwise comparison.
} 